\title{
Posttraumatic Syringomyelia with Holocord Involvement: A Case Report
}

Jong Min Lee, In Uk Lyo, Soon Chan Kwon, Hong Bo Sim

Department of Neurosurgery, Ulsan University Hospital, University of Ulsan College of Medicine, Ulsan, Republic of Korea
Received: August 31, 2018

Revised: September 11, 2018

Accepted: September 12, 2018
Posttraumatic syringomyelia occurs in nearly half of all spinal cord injury (SCI) patients. However, there haves been very few cases of syringomyelia of the entire spinal cord, known as holocord syringomyelia. Here, we discuss a case of posttraumatic holocord syringomyelia in the light of the literature review. A 43-year-old man presented with ongoing motor weakness of the left upper extremity. He had a history of SC with a spinal fusion operation 5 years ago. Magnetic resonance imaging (MRI) of the spine revealed an expansive high signal intensity lesion in the spinal cord from the medulla to T12. Total T8 laminectomy and syringopleural shunt placement were performed. The patient's motor weakness of the left upper extremity recovered and the extent of syrinx decreased remarkably at the 1 year follow up MRI. Physicians should consider holocord syringomyelia as a possibility in patients with ongoing neurologic deficit with a history of SCI.

Key Words: Magnetic resonance imaging; Spinal cord injuries; Syringomyelia

\section{INTRODUCTION}

Syringomyelia is a disease characterized by cystic formation, or syrinx, within the spinal cord and is accompanied by a variety of symptoms. It can be induced by several causes, including Chiari malformation, spinal cord injury (SCI), spinal cord neoplasms, and any other factors that can induce inflammatory conditions. Among the SCI patients, nearly half undergo spinal cystic change, i.e., posttraumatic syringomyelia ${ }^{4,7)}$. Among these patients, less than $10 \%$ experience symptomatic syringomyelia ${ }^{3,677}$; however, there have been very few cases of syringomyelia involving the entire spinal cord, or holocord syringomyelia. The relatively few cases of holocord syringomyelia make it difficult for medical staff to establish a treatment strategy. Here, we report a case where a patient with holocord syringomyelia was treated with a syringopleural shunt.

\section{CASE REPORT}

A 43-year-old man was presented to the outpatient department of Neurosurgery with ongoing motor weakness of the left upper extremity. The patient's symptom began with paresthesia in his left arm, and over several months, the symptom gradually worsened. Weakness of the patient's left arm also appeared. The patient had a history of SCI due to a traffic accident 5 years ago. At the time of injury, the severity of the injury was of American Spinal Injury Association Impairment Scale A. Fusion of T12-L1 was performed for flexion-distraction injury of T11/12. After the operation, sequelae of paraplegia and sensory impairment under T10 sensory dermatome were present; however, upper extremity motor control was intact leaving the patient able to undertake wheelchair ambulation.

The patient was first evaluated using magnetic resonance imaging (MRI). Brain MRI revealed syrinx at the level of medulla. Therefore, a cervico-thoracic spine MRI was performed to deter-
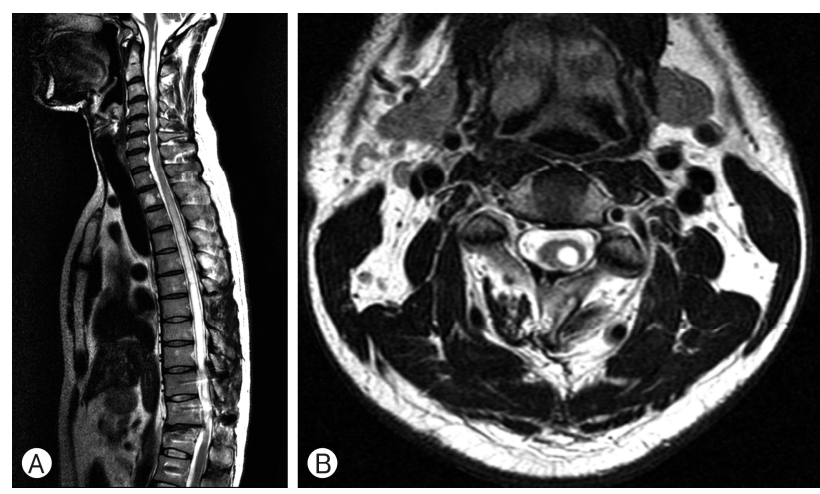

Fig. 1. (A) Sagittal T2-weighted spin echo magnetic resonance image (MRI) shows marked dilatation of the central canal, consistent with syrinx cavity from medulla extending to the level of prior injury at T10-11. A prior transpedicular screw can be seen from T10 to L1. (B) Axial T2-weight MRI shows a marked hollow cavity lesion in the spinal cord. 


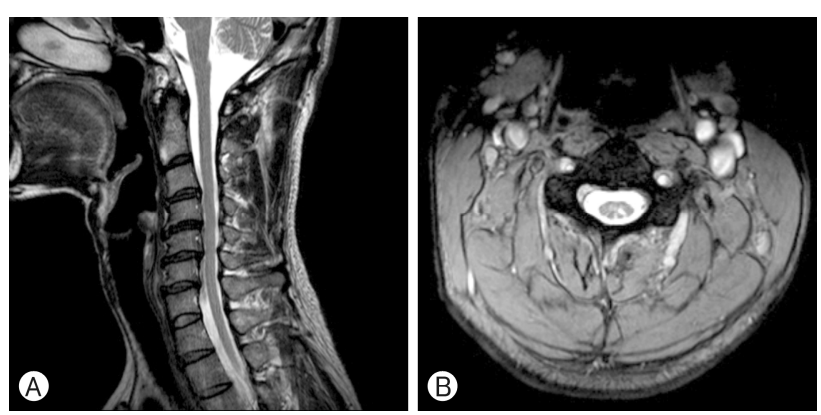

Fig. 2. (A, B) Sagittal and axial T2-weighted spin echo magnetic resonance image shows marked decreased volume and extent of syringomyelia.

mine if there was any associated pathology related to the previous operation site. On the cervico-thoracic MRI, an expansive high signal intensity lesion on the spinal cord from the level of the medulla to T12 on T2 spin echo image was noted (Fig. $1 \mathrm{~A}, \mathrm{~B})$.

The patient was admitted and underwent total T8 laminectomy and syringopleural shunt placement. The clinical course of the patient was tolerable and he was discharged on the $14^{\text {th }}$ postoperative day. The patient's left upper extremity motor weakness recovered and the extent of syrinx decreased remarkably on 1 year follow up MRI (Fig. 2A, B).

\section{DISCUSSION}

Syrinx, including the entire spinal cord, has been reported in chiari malformations; however, cases reported in posttraumatic SCI patients are extremely rare. Approximately 10 cases of posttraumatic syringomyelia with holocord involvement have been reported in the literature ${ }^{1,2,5,7,8)}$. Generally, symptoms of syringomyelia occur 1 to 34 years after their initial SCI. Unlike common posttraumatic syringomyelia, patients with posttraumatic holocord syringomyelia were diagnosed 19 to 34 years after the primary injury ${ }^{1,2)}$. Awai and Curt $^{2)}$ described cases of posttraumatic holocord syrinx where 4 patients were diagnosed with posttraumatic holocord syringomyelia. In contrast to this, However, the patient in our case study was diagnosed relatively quickly, after 5 years.

It is known that the duration of syrinx formation is mainly affected by the degree of injury and age at the time of injury. Krebs et al. ${ }^{7)}$ described 138 patients with posttraumatic syringomyelia. They verified that injury severity and age were significant predictors for the early ( 5 years after SCI) formation of syringomyelia. However, since only two of the patients had holocord syringomyelia, it is difficult to accurately correlate the time to clinical manifestation of holocord syringomyelia and other predictors.

It is known that numerous abnormalities produced by spinal injury could disturb cerebrospinal fluid (CSF) flow and cause syrinx enlargement ${ }^{4)}$. Lee et al. ${ }^{8)}$ described 7 patients treated with various surgical methods including adhesiolysis, duroplasty and shunt. In that study, authors suggested that the restoration of CSF flow dynamics alone by adhesiolysis and/or duroplasty was more effective than simple drainage of the syrinx. However, the study was not specifically confined to the holocord syrinx and shunt operations were performed in all 3 cases of holocord syrinx patients. Some other studies ${ }^{1,5)}$ described a patient with posttraumatic holocord syringomyelia treated with a syringosubarachnoid shunt. In those studies, the postoperative course during acute inpatient rehabilitation was unremarkable, but the long term effects are unknown due to follow-up loss. In our case, there was no definite evidence of arachnoid adhesion or localized CSF obstruction site in preoperative MRI of the spine. So we did shunt operation rather than adhesiolysis. Also, unlike previous studies, the patient has been on follow-up continuously for approximately 2 years without any neurological change.

\section{CONCLUSION}

Here, we present a case of holocord syringomyelia which led to an ongoing neurologic deficit. There have been very few cases of posttraumatic syringomyelia with holocord involvement. Although development of symptomatic syringomyelia takes a long time, physicians should consider conditions such as holocord syringomyelia in patients with ongoing neurologic deficit who had a history of SCI. Such a reasonable consideration will lead to the most suitable surgical treatment.

\section{CONFLICT OF INTEREST}

No potential conflict of interest relevant to this article was reported.

\section{REFERENCES}

1. Amin I, Ilizarov G, Chowdhury N, Kalva S: Post-traumatic syringomyelia with holocord involvement: a case report. Spinal Cord Ser Cases 3:17054, 2017

2. Awai L, Curt A: Preserved sensory-motor function despite largescale morphological alterations in a series of patients with holocord syringomyelia. J Neurotrauma 32:403-410, 2015

3. Backe HA, Betz RR, Mesgarzadeh M, Beck T, Clancy M: Posttraumatic spinal cord cysts evaluated by magnetic resonance imaging. Paraplegia 29:607-612, 1991

4. Brodbelt AR, Stoodley MA: Post-traumatic syringomyelia: a review. J Clin Neurosci 10:401-408, 2003

5. Ghobrial GM, Beygi S, Viereck MJ, Heller JE, Sharan A, Jallo J, et al.: C-5 palsy after cerebrospinal fluid diversion in posttraumatic syringomyelia: case report. J Neurosurg Spine 22:394-398, 2015 
6. Ko HY, Kim W, Kim SY, Shin MJ, Cha YS, Chang JH, et al.: Factors associated with early onset post-traumatic syringomyelia. Spinal Cord 50:695-698, 2012

7. Krebs J, Koch HG, Hartmann K, Frotzler A: The characteristics of posttraumatic syringomyelia. Spinal Cord 54:463-466, 2016

8. Lee JH, Chung CK, Kim HJ: Decompression of the spinal subarachnoid space as a solution for syringomyelia without Chiari malformation. Spinal Cord 40:501-506, 2002 